\title{
Oskar Loorits ja liivlased
}

Renāte Blumberga

Käesolevas kirjutises tahaksin rääkida Oskar Looritsast mitte kui liivlaste uurijast, vaid kui liivlaste sõbrast ja liivlaste toetamise liikumise rajajast Eestis ja Soomes. Oskar Looritsa teekond liivlaste juurde algas 1920. aasta juunikuus Lūži (läti k Lūžnas, omastav Lūžnuu) külast, kus ta viibis Tartu Ülikooli läänemeresoome keelte professori Lauri Kettuse abilisena. Kaasasõitjat valides otsis professor üliõpilaste hulgast andekat noort, keda võiks valmistada ette oma järglaseks ja ekspeditsiooni ajal välja õpetada, praktiline abi polnud nii oluline. L. Kettusele jäid silma kaks üliõpilast - Julius Mägiste ja Oskar Loorits. Ta valis viimase.

Professor Kettunen ei kahetsenud kunagi oma valikut - O. Loorits abistas teda uurimistöös juba alates esimestest ekspeditsioonipäevadest (Kettunen 1920). Peale selle hakkas ta varsti tavaliste keelenäidete kirjapanemise kõrval tundma sügavamat huvi liivi etnograafia ja rahvaluule vastu (Kettunen 1948: 111). Nagu näitavad hilisemad sündmused, oligi see Oskar Looritsa tõeline kutsumus kuigi lõplikku valikut polnud tal kerge teha - ja temast ei saanud L. Kettuse järglast läänemeresoome keelte alal.

See 1920. aasta suve ekspeditsioon, enne mida mehed polnud kindlad, kas liivlasi veel üldse elus on (Kettunen 1920), jäigi nende ainsaks ühiseks käiguks selle rahvakillu juurde. Ja just selle kogumismatka ajal sai alguse Eestis ja Soomes liivlaste toetamise liikumine, mille hälli juures seisid eestlane Oskar Loorits ja soomlane Lauri Kettunen.

Üliõpilaspõlves peitis O. Loorits end sageli professor L. Kettuse nime taha, arvates põhjendatult, et niiviisi saavad tema sõnad ja teod suurema kaalu. Tegutsedes koos liivlaste päästmise nimel, kasvas üliõpilase ja professori suhe mõttekaasluseks. Sellest annab tunnistust hulk Oskar Looritsa kirju Lauri Kettusele, kus ta mõtiskleb nii liivlaste kui ka eesti akadeemiliste ringkondade olukorra üle.

Oskar Looritsat peeti nii Lätis kui ka Eestis mässajaks, isegi skandaalitsejaks. Tõsi, ta polnud diplomaat ja ütles otse välja, mida mõtles, kuigi see tegi tema elu sageli keerulisemaks.

http://haldjas.folklore.ee/tagused/nr24/blumberga.pdf 


\section{Renāte Blumberga}

Kuid liivlaste puhul oli asi hoopis teisiti. Oskar Loorits oli kõikide lemmik ja sai isegi kaks liivikeelset hüüdnime - Vāldapää (valgepea) ja Nūorizānd (noorhärra). Mitmes kodus võeti teda vastu kui oma poega. Ta olevat saanud hästi läbi ka lastega. Vanema põlvkonna mälestustes 1920. ja 1930. aastatest naljalt muude teadlaste nimesid ei kohta kui Oskar Loorits ehk Vāldapää. Ka on paljudel meeles temaga seotud juhtumid.

Minu perekonnas räägitakse näiteks järgmist lugu, mida kuulsin smakordselt oma sugulaselt Paulīne Klavinalt, hiljem leidsin selle ka avaldatuna (Lindsaar 1969: 139). 1948. aastal oli seda Saksamaal paguluses rääkinud eesti kirjanikule Peeter Lindsaarele Oskar Looritsa liivlasest ristitütar Silvija Bertholde. Tema ema olla kord raseduse ajal heitnud puhkama ja uinunud. Ärgates näinud ta toa keskel valgepäist võõrast meest ja ehmatanud väga. Kui tumedate juustega vanematele sündis linalakk tütar, arvanud külarahvas, et selle põhjuseks on Oskar Looritsa tekitatud ehmatus. Süüdlane oli palutud hiljem ristiisaks ja ta nõustunudki.

Aastal 1920 oli liivlaste olukord järgmine. Esiteks tähendas Esimese maailmasõja põhjustatud sundevakuatsioon paljudele kuueaastast pagulust Läti sisemaal, Eestis või Venemaal. Tulemus oli see, et liivlaste noorem põlvkond unustas osaliselt oma keele. Teiseks, liivi keelt kasutati ainult kodukeelena, ka ei olnud liivikeelset kirjandust. Matteuse evangeeliumgi oli viimati välja antud õige ammu - 1880. aastal. Kolmandaks, Liivi rannal valitses vaesus ja liivlased polnud saanud kuigi palju haridust. Oli selge, et kui ei võeta midagi ette, ootab liivlasi kiire assimilatsioon ehk lätistumine.

Eelmainitud põhjustest tulenesid liivlaste toetajate tegutsemise peasuunad. Nimelt hariduse edendamine, liivikeelse lugemisvara väljaandmine ja liivlaste ühiskondliku organisatsiooni asutamine. Kohe pärast esimest ekspeditsiooni võeti Akadeemilise Emakeele Seltsi programmi moraalse ja materiaalse abi andmine liivlastele. Esimene reaalne töö oli 1921. aastal seltsi poolt Tartus välja antud Esimene Liivi lugemik (Kettunen \& Loorits 1921) Ametlikult olid selle koostajad Lauri Kettunen ja Oskar Loorits, tegelikult koostas Oskar Loorits selle üksinda (Kettunen 1948: 144-145).

Juba 1920. aasta sügisest ilmusid Eesti lehtedes regulaarselt Oskar Looritsa artiklid liivlastest ja nende olukorrast. Alguses üsna süütud lood, näiteks "Pildikesed liivlastest" (Loorits 1920), hiljem aga üha teravamad artiklid, näiteks "Liivi rahva elu ja surma küsi- 


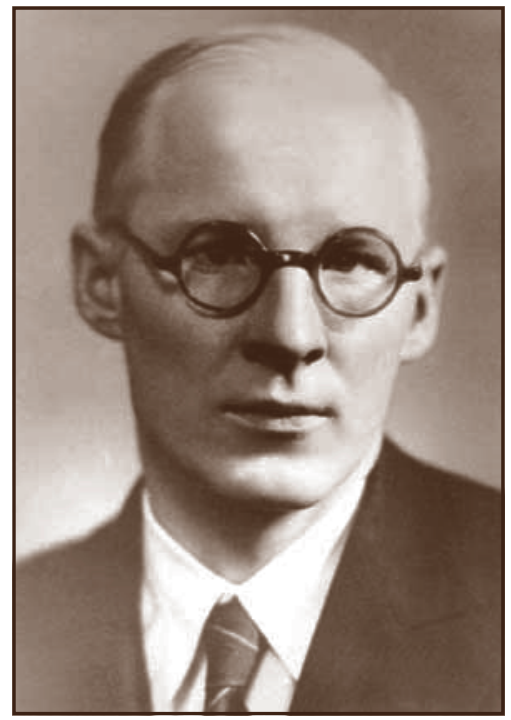

Foto 1. Oskar Loorits (1900-1961). Foto Eesti Rahvaluule Arhiivi fotokogust.

mus" (Loorits 1934). Üha enam süüdistati Lätit hoolimatuses liivlaste vastu. Peab tunnistama, et kriitika oli põhjendatud. Esimesed ebameeldivad signaalid tulid Lätist juba aastail 1922-1923. Liivlased ei saanud isegi oma valda. Raskusi oli ka Liivi Seltsi (Lĩvõd $\overline{I t}$ ) asutamisega. Alles 1923. aasta veebruaris kinnitasid Läti ametlikud võimud teisel katsel (Kettunen 1922) Liivi Seltsi põhikirja, mille koostamisest olevat 1922. aasta suvel osa võtnud ka Oskar Loorits (Šuvcāne 1998: 114). Kohe pärast põhikirja esitamist kuulas Läti kaitsepolitsei üle kolm liivlast, kes olid allakirjutanute hulgas. Näiteks Kōrli Staltelt küsiti, kas see on tõsi ja kuidas seda seletada, et köster tegutseb Läti riigi vastu ja et Liivi rand (Līvõd Rānda) tahab end allutada Eestile või Soomele (Loorits 1923a). Nagu edaspidised sündmused näitasid, polnud see ainus kord, mil Lätis tõsteti üles Liivi ranna Eestiga ühinemise teema.

Oskar Looritsa hoiak liivlaste küsimuses vaheldus kõige optimistlikumast täieliku pessimismini. Näiteks 1923. aasta suvel, saanud Lauri Kettuselt teate, et Suomalaisuuden Liitto kingib Liivi Seltsile 1000 marka (Kettunen 1923), teatas O. Loorits, et tema 


\section{Renāte Blumberga}

energia on tõusnud 500 kraadi võrra ja ta juba fantaseerib sellest, kuidas oleks tarvis minna mõneks kuuks Liivi randa rajama Liivi Seltsile, koolile ja vallale tugevat alust (Loorits 1923b). Ta mõtiskles sellest, kuidas rajada Eestis ja Soomes liivlaste toetajate võrk, mille liikmed maksaksid kas 100 marka kuus või ühekordset liikmemaksu 5000 marka, et muretseda selle raha eest liivlastele kirjandust ja palju muudki vajalikku (Loorits 1923b).

1920. aastatel oli just O. Loorits see, kes aitas Liivi Seltsi konkreetse tööga. Sügisel ja talvel 1923-1924 viibis ta pidevalt Lätis, nii Riias kui ka Irel (läti nimega Mazirbe). Sel ajal tegeles ta oma teaduslikust tööst vabal ajal n-ö liivi asjaga. Näiteks 18. novembril 1923, Läti iseseisvuspäeval õnnistati Irel sisse Liivi lipp ja näidati seda esimest korda avalikult. Külalised Soomest ja Eestist tulid peole ja sõitsid kohe pärast pidu ära. Kõik läks seejärel nii, nagu Oskar Loorits oli kartnud. Kui pidulikud kõned ja paraadid said seljataha, tuli vaesel Vāldapääl jääda üksi kohale pingelist tööd tegema, kuigi ta pidanuks olema juba tagasi Riias ja jätkama oma teadustööd. Ent tal tuli veeta mitu päeva köster Kōrli Stalte juures, et koos välja töötada liivi keele grammatika terminoloogiat - see oli väga vajalik liivi keele õpetamiseks koolides. Töö pakkus rahuldust juba seetõttu, et andis võimaluse näha rõõmupisaraid vana köstri silmades. Hullem lugu oli Liivi Seltsi asjaajamise kordaseadmisega (Loorits 1923c). Samuti oli just Oskar Loorits see, kes, tundes kõige paremini kohalikke olusid, koostas (vähemalt 1923. aastal) nende liivlaste nimekirja, kes pidanuks saama eestlastelt jõulukingitusi (Loorits 1923c; 1923d).

Oskar Loorits lootis kogu aeg, et Läti võtab lõpuks liivlaste eest hoolitsemise enda peale. Kas või sellepärast, et Liivi Selts siiski registreeriti, kuigi raskustega, ja liivi keelt lubati õpetada mõnedes ranniku koolides, kuigi ainult valikainena. Need lootused kadusid 1924. aasta veebruaris, kui O. Loorits sai eitava vastuse Läti Kultuurifondilt. Ta oli esitanud kolm projekti. Esimene nägi ette palgalisa liivi keele õpetajatele, teine anda välja liivi keele õpik algkoolidele ja kolmas toetada raamatukogu rajamist, milles oleks liivikeelseid raamatuid. Peale selle hakkas Läti ajalehtedes ilmuma üha ebaobjektiivsemat informatsiooni liivlastest ja nende uurijatest.

Näiteks ajaleht Latvis kirjutas:

Juba mõnd kuud eestlane Loorits käib ringi Popeni ja Dondangeni rannas liivlasi "uurides". Kuulub jutte, et liivlaste "uurimise" ettekäändel siia jäävat elama edaspidi pysivalt 
1-3 eestlast. [---] Mõned liivlased olevat palunud Eesti Riigivanemat, et see avitaks yhendada Popeni ja Dondangeni rannariba yheks vallaks. Jõuludeks Eesti Akadeemiline Klubi saatis liivi lastele kinke. Riiklikult mõtlejad liivlased ei saa aru, mispärast nimetatud Klubi ei kinkinud annetusi esiteks oma veeuputuse all kannatanud kodumaalastele (Loorits 1924d).

Äraütlemine ja lehejutud vapustasid Oskar Looritsat sedavõrd, et ta hakkas organiseerima kirjutisi Eesti ja Soome lehtedesse:

Eestis ja Soomes peab visatama ükskord pomm: vallaasi, kultuurfondi asi, Hõimuklubi ja minu isiku teotamine ja lõpuks valeteated rannalt! (Loorits 1924a).

Professor Lauri Kettunen võiks kirjutada Päevalehte ja Helsingin Sanomatesse. Postimehele võiks kirjutada ka keegi teine liivi toetajatest. Martti Haavio võiks panna paar artiklit Uusi Suomisse, tema ise aga hakkavat kirjutama Läti lehtedesse (Loorits 1924b).

Kuid Jaunākās Zinas ei avaldanud Oskar Looritsa pikka kirjutist, milles ta kirjeldas liivlaste tegelikku olukorda (Loorits 1924c). Selle asemel avaldas sama ajaleht lühikese jutukese "Veel Kuramaa liivlastest", milles öeldi:

Tartu Ülikooli magister ja stipendiaat Oskar Loorits on saatnud meile pikema artikli, milles ta mõistab hukka Läti ajakirjanduse pahatahtlikke artikleid liivlastest ja eriti ajalehte Latvis (Vèl par lïbjiem Kurzemē 1924).

Järgnes väga lühike artikli sisu ümberjutustus, mille lõppu oli lisatud järgmine toimetuse märkus:

Lätlastel ei või olla midagi selle vastu, et meie naabrid, Eesti ja Soome teadlased tunnevad huvi välja surnud liivi rahva riismete vastu, nii kaua, kui sel huvil on puht teaduslik ja kultuuriline iseloom. Neis piirides saame me alati üksteisest aru.

See seisukoht Oskar Looritsat ei peatanud. Tegelikult tegutses ta 1920. aastatel nii liivlaste uurija kui ka liivlaste toetamise liikumise aktivistina, jättes siiski järk-järgult viimase valdkonna teiste hõimuliikumisaktivistide vedada. 1930. aastatel tegi O. Loorits liivlaste heaks juba rohkem: kasutades oma teadlaseautoriteeti, kaitses ta avalikes ettekannetes ja artiklites liivlaste õigust olemasolule. 


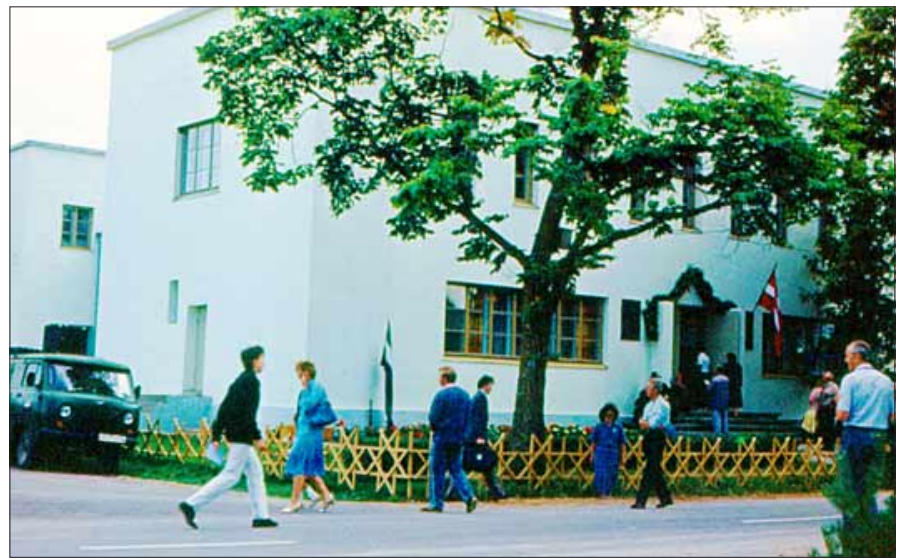

Foto 2. Liivi rahvamaja valmis 1939. aastal ja on püsinud tänini. Siin asub ka tänapäeval liivi liikumise keskus. Foto Eha Viluoja 1999.

Eelmainitud tegevus viiski selleni, mida nimetatakse eesti folkloristi Oskar Looritsa Lätist väljasaatmiseks Baltimaade ajaloo kongressi ajal 1937. aasta augustis. Läti ajalookirjanduses leidub ainult üks uurimus, kus on seda küsimust puudutatud (Šcerbinskis 1998), kusjuures selleski uurimuses pakutud versioon toimunust ei lähe kokku O. Looritsa enda sündmuste kirjeldusega, mille võib leida tema kirjadest Lauri Kettusele. Läti näitas Oskar Looritsat piiririkkujana, kellel läks Läti piiri ületamine korda ainult sellepärast, et Eesti teadlastel oli kollektiivne kutse kongressile ja kõikidel olid haridusministeeriumi load, seetõttu, kartes külalisi solvata, ei olnud piirivalvurid kontrollinud ebasoovitavate isikute nimekirja. Nii jõudis O. Loorits Riiga, kuigi ta oli kuulutatud juba 1935. aastal Lätis ebasoovitavaks isikuks (Šcerbinskis 1998).

Oskar Loorits ise väidab, et ta ületas takistamatult Läti piiri 20. ja 24. jaanuaril 1937, mida tõestavad ka templid tema passis (Loorits 1937a). Teist korda tuli ta Lätisse sama aasta 23. juulil, s.o peaaegu kuu aega enne kõnealust kongressi. Kongressi alguseni töötas O. Loorits Liivi rannikul Soome-Ugri Seltsi rahastatava liivi muinasjuttude kogumiku käsikirja kallal ega aimanudki, et on ebasoovitav isik. Ta kavatses tööd pärast kongressi jätkata, mistõttu suurem osa käsikirju jäi Irele Kōrli Stalte kätte, et see need liivi keelest 
saksa keelde tõlgiks. Veel novembri alguses ei olnud Oskar Loorits käsikirju tagasi saanud (Loorits 1937b; 1937c). Lisan, et see liivi muinasjuttude kogumik, mis oli kavas avaldada liivi ja saksa keeles, ei näinud kunagi trükivalgust.

Alles 20. augustil, kongressi viimasel päeval sai O. Loorits Riia Eesti saatkonna kaudu teate, et peab ebasoovitava isikuna Lätist lahkuma. Põhjusena mainis saatkonna sekretär Oskar Looritsa ettekandeid ja artikleid liivi küsimusest, nimelt "Liivi rahva elu ja surma küsimus" (Loorits 1934; 1937d), ning kõnet Kalevala peol Soomes (Loorits 1936). Sisuliselt polnud neis midagi uut, kui võrrelda Oskar Looritsa eelmiste esinemistega - samad etteheited Lätile hoolimatuse pärast liivlaste vastu. Uus on aga see, et Lätis oli oluliselt muutunud poliitiline õhkkond.

Hiljem, selgitades asja Eesti välisministeeriumis, õnnestus Oskar Looritsal täiendada oma pattude nimekirja veel kolmega. Esiteks, initsiaalide O. L. (hiljem osutus Otto Liivaks) all ilmunud kirjutis Päevalehes. Teiseks, ebaseaduslik piiriületus. Kolmandaks, kihutustöö liivlaste hulgas, et nad nõuaksid Liivi ranna viimist Eesti haldusesse, ja kui see õnnestub, võivad eestlased teha Riia lahest oma Gibraltari, kasutades uut territooriumi ja Saaremaa Sõrve säärt (Loorits 1939).

Enne 1937. aasta jõule sai Oskar Loorits Eesti välisministeeriumi ametliku teate, et lätlased annavad talle võimaluse muuta ära oma ebasoovitava isiku staatus. Tal lubatakse minna jõulude ajal Riiga tingimusel, kui ta tagasi tulles annab artiklites ja intervjuudes ainult Lätile sõbralikku informatsiooni. Sellele vastas O. Loorits, et teda ei huvita teha midagi tellimise peale, vaid ainult südametunnistuse järgi. Sellega asi lõppes (Loorits 1939) ja Oskar Loorits ei käinud enam kordagi Liivi rannas. Oma mitmeaastase tegevuse liivlaste heaks võttis ta kokku järgmiselt:

Oma sõitudes liivlaste juurde pole ma kunagi tegelnud poliitikaga ega ole Läti siseasjadesse sekkunud. Olen ka selles kindel, et teisedki soome ja eesti teadlased ja hõimuliikumise aktivistid pole kunagi läinud sinna poliitikat tegema, vaid kultuuritööd, mis pole kunagi lätlaste suhtes vaenulik olnud (Loorits 1937d).

Kuni oma surmani jäi Oskar Loorits ustavaks liivlaste uurimisele, kuigi publikatsioone sellel teemal ilmus hilisematel aastatel üsna vähe. Vähem kui aasta enne surma, 19. jaanuaril 1961 kirjutas Os- 


\section{Renāte Blumberga}

kar Loorits uuelt kodumaalt Rootsist lähedasele sõbrale ārmaz propesor-izand (armas härra professor - liivi k) Lauri Kettusele järgmised read, mida võiks nimetada tema vaimseks testamendiks:

Aga surma tunnen ukse taga ning mõtlen murega, kui palju, kui palju mu elutööst jääb pooleli, kõnelematta kodumaale mahajäänd valmis käsikirjadest (määratu monograafia setukeste imede-ja ikoonideusust, liivi rahvajutud ja bibliograafia, mü̈̈did maailma loomisest jne.) - jah, ühes keldris Tartu ligidal nad on nü̈̈d rottide närida, et kinnitada meie tõdemust: tühi töö ja vaimu närimine [---] Olen tõmbund tagasi avalikust elust, isegi Soomet ma pole pärast 1939 enam külastada tihand, kuigi mu "Liivi rahva usund" IV seisis seal Lauri Posti algatusel üle kümne aasta, oodates asjatult SKS-s [Soome Kirjanduse Selts - R. B.] trükkitoimetamist. Nü̈̈d seisab mul riiuleil selliseid käsikirju pikk rida (osa Dublini deponeeritud), kuid nü̈̈d tunnen saatuselle alistunult, et olengi ju vaibund minevikku, kellest tänapäev möödub vaikides, Issandalle tänu kõige eest! (Loorits 1961).

\section{Kirjandus ja allikad}

Kettunen, Lauri 1920. Kiri H. Ojansuule. 13. juuni. Suomalaisen Kirjallisuuden Seuran kirjallisuusarkisto (SKS KA) 415: 19: 33.

Kettunen, Lauri 1922. Kiri Suomalaisuuden Liittole. 4. detsember. Suomen Kansallisarkisto (SKA). Suomalaisuuden Liiton arkisto (SLA). Saapuneet kirjeet. 1916-1922. Ea 3.

Kettunen, Lauri 1923. Kiri Suomalaisuuden Liittole. 6. juuni. Suomen Kansallisarkisto (SKA). Suomalaisuuden Liiton arkisto (SLA). Saapuneet kirjeet. 1923-1924. Ea 4.

Kettunen, Lauri 1948. Tieteen matkamiehen uusia elämyksiä: Murrosvuodet 1918-1924. Porvoo \& Helsinki: Söderström.

Kettunen, Lauri \& Loorits, Oskar (koost) 1921. Esimene Liivi lugemik = Ežmi Lived lugdebrõntez. Tartu.

Lindsaar, Peeter 1969. Iltarusko liiviläisten rannikolla. Karjalan Heimo 9/10, lk 135-140.

Loorits, Oskar 1920. Pildikesed liivlastest. Postimees: Hommiku-väljaanne 204-206. 17., 19. ja 20. oktoober. Tartu. 
Loorits, Oskar 1923a. Kiri Lauri Kettusele. 9. märts. Seppo Suhose arhiiv. Loorits, Oskar 1923b. Kiri Lauri Kettusele. 3. august. Seppo Suhose arhiiv. Loorits, Oskar 1923c. Kiri Lauri Kettusele. 25.-27. november. Seppo Suhose arhiiv.

Loorits, Oskar 1923d. Kiri Lauri Kettusele. 7.-11. detsember. Seppo Suhose arhiiv.

Loorits, Oskar 1924a. Kiri Lauri Kettusele. Enne 20. veebruari. Seppo Suhose arhiiv.

Loorits, Oskar 1924b. Kiri Lauri Kettusele. 5. veebruar. Seppo Suhose arhiiv. Loorits, Oskar 1924c. Kiri Lauri. Kettusele. 20. veebruar. Seppo Suhose arhiiv.

Loorits 1924d = Latvis $1923 \mathrm{nr}$ 682. 23. decembris (tsiteeritud artikli tõlget Oskar Looritsa kirjast, säilitatud tema ortograafia): Kiri Lauri Kettusele. Veebruar 1924. Seppo Suhose arhiiv.

Loorits, Oskar 1934. Liivi rahva elu ja surma küsimus. Päevaleht 291, 22. oktoober, lk 4.

Loorits, Oskar 1936. Kõne Kalevala peol Soomes. Kalevalaseuran Vuosikirja 16. Helsinki: Söderström, lk 88-89.

Loorits, Oskar 1937a. Kuidas ma läksin üle Läti piiri? Postimees 271, 7. oktoober, lk 3.

Loorits, Oskar 1937b. Kiri Soome-Ugri Seltsile. 4. november. Suomalaisen Kirjallisuuden Seuran kirjallisuusarkisto (SKS KA) 559: 5: 4.

Loorits, Oskar 1937c. Kiri Lauri Kettusele. 24. august. Seppo Suhose arhiiv. Loorits, Oskar 1937d. Liivin kansan elämän ja kuoleman kysymys. Suomalainen Suomi: Suomalaisuuden liiton kulttuuripoliittinen aikakauskirja 6, lk 339-407.

Loorits, Oskar 1939. Kiri Lauri Kettusele. 10. märts. Seppo Suhose arhiiv. Loorits, Oskar 1961. Kiri Lauri Kettusele. 19. jaanuar. Seppo Suhose arhiiv. Šcerbinskis, Valters 1998. Lībiešu jautājums Latvijas attiecībās ar Somiju un Igauniju (1920-1940). Latvijas Arhīvi 1, lk 60-64.

Šuvcāne, Valda Marija 1998. Līvu savienības darbības sākums. Lībiešu gadagrāmata $=$ Līolist āigastrōntoz. Mazirbe: Līvod rānda \& Līvo kultūr sidām.

Vēl par lībjiem Kurzemē 1924. Jaunākās Ziṇas 40, 18. veebruar. 